\title{
Undergraduate Students Benefits from involvement in K-12 Outreach
}

\section{Dr. Angela R Bielefeldt, University of Colorado, Boulder}

Angela Bielefeldt is a professor at the University of Colorado Boulder in the Department of Civil, Environmental, and Architectural Engineering (CEAE) and Director for the Engineering Plus program. She has served as the Associate Chair for Undergraduate Education in the CEAE Department, as well as the ABET assessment coordinator. Professor Bielefeldt was also the faculty director of the Sustainable By Design Residential Academic Program, a living-learning community where students learned about and practice sustainability. Bielefeldt is also a licensed P.E. Professor Bielefeldt's research interests in engineering education include service-learning, sustainable engineering, social responsibility, ethics, and diversity.

\section{Dr. Greg Rulifson PE, USAID}

Greg is currently an AAAS Science and Technology Policy Fellow. Greg earned his bachelor's degree in Civil Engineering with a minor in Global Poverty and Practice from UC Berkeley where he acquired a passion for using engineering to facilitate developing communities' capacity for success. He earned his master's degree in Structural Engineering and Risk Analysis from Stanford University. His PhD work at CU Boulder focused on how student's connections of social responsibility and engineering change throughout college as well as how engineering service is valued in employment and supported in the workplace. He taught in the Humanitarian Engineering program at the Colorado School of Mines from 2015 to 2018. 


\title{
Undergraduate Student Benefits from Involvement in K-12 Outreach
}

\begin{abstract}
This research explored the types of benefits that undergraduate students derive from engaging in outreach activities with K-12 students. The research was conducted post hoc, using transcripts from longitudinal interviews with 34 undergraduate students attending 5 different institutions. The transcripts were analyzed using emergent thematic coding, as well as looking specifically for evidence related to the four criteria for effective learning from Dewey (generate interest, worthwhile intrinsically, awaken need to learn, and extended time span). When asked what they were doing outside of class and school work, fifteen students shared their experiences participating in activities with K-12 students. For example, one female student participated in significant outreach activities for three years through various co-curricular and extracurricular groups such as the Society of Women Engineers and the Earthquake Engineering Research Institute. Two other women were paid to facilitate engineering activities in K-12 classrooms during all four years of their undergraduate experience, thus meeting Dewey's time span criteria. Themes that emerged from students' descriptions of their K-12 outreach experiences included how fun it was, a good break from the stress of classes and studying; this aligns with Dewey's criteria of generating interest. This balance and reconnecting with the fun of engineering might help students persist in their engineering studies. The teaching aspects of these programs may solidify engineering concepts for the undergraduates. A number of the students also discussed the idea of giving back and serving as a role model for kids, aligning with Dewey's criteria of being worthwhile intrinsically. A few students discussed issues related to social justice, implying the K-12 experience influenced their social responsibility attitudes. Other attitude impacts and a sense of community were also described. The specific outcomes for college students likely vary with different types of K-12 engagement. Based on this work, we believe Dewey's model would be useful for faculty and staff designing K-12 outreach programs who wish to optimize the beneficial learning outcomes for college students.
\end{abstract}

\section{Introduction}

It is common for colleges to send university students into the community to engage in outreach activities with local K-12 students. The goals of these activities typically include getting kids interested in and excited about engineering, creating a 'pipeline' of future engineering students $[1,2]$. The assessment around these outreach activities is often focused on the impacts to the K12 kids (e.g. [2-4]): Do they gain knowledge about engineering? Increase their interest in engineering? In contrast, the research question explored in this work was: What benefits do undergraduate engineering students derive in association with their activities with K-12 students?

Undergraduate student development is a common goal for K-12 outreach programs [1], particularly when these programs are aligned with service-learning activities embedded in courses (e.g. [5]). Some studies have examined the impacts of programs engaging with K-12 students on the college students. Carberry et al. [6] used surveys, knowledge assessments, and observations to determine that students participating in the Student Teacher Outreach Mentorship Program (STOMP) at Tufts University, which sent college students into K-12 classrooms, increased the college students' understanding of the engineering design process; they also stated 
that previous research established that the program increased citizenship and communication skills. Engaging in various K-12 outreach activities were also found to benefit college students' communication skills by $[2,3,5,7,8]$. Enhanced leadership [8] and technical skills $[2,8]$ may also result. Faculty advisors for student chapters of engineering professional societies believe that student participation in K-12 outreach activities contributes to their education on ethics and societal impacts of engineering [9]. Increased retention among college students serving as mentors for K-12 kids via civic engagement activities is possible, "although not yet extensively studied" [10]; note these data relate to persistence of undergraduates to earn college degrees in general, not specific to engineering.

The grounding theories related to this research are drawn from those applied to service-learning (SL), where the student engaging in a service activity experiences rich learning outcomes. Giles and Eyler [11] proposed that Dewey's [12] theories were a good fit for SL, based on learning from experience and the transaction between the learner and environment. While K-12 outreach activities likely fulfill these SL criteria, many of these programs would fail to meet a third important SL aspect that requires critical reflection of the learner on the experience. Unless embedded within a course as a service-learning activity (e.g. [13]), there may not be structured reflection. This is particularly true in co-curricular activities, where advisors may worry that formal reflection would deter college students from participating. However, the reflection could occur informally via a group discussion.

Giles and Eyler [11] cite Dewey's [12] four criteria for projects to be truly educative. The four criteria are: generate interest, worthwhile intrinsically, problems that demand new information, and cover a considerable time span. K-12 activities are often designed to be fun, so they are likely to generate interest on behalf of both the college student and K-12 kids, thus fulfilling criterion 1. Next, the project must be worthwhile intrinsically; it is likely that K-12 outreach will meet this criterion from the perspective of the college student feeling like they are inspiring the next generation. It is possible that some program types may fulfill this to a lesser degree, if the college students feel they are just "babysitting" in an afterschool program, for example. The third criterion is "must present problems that awaken new curiosity and create a demand for information" [11, p. 80]. If the college students are mentoring creative projects with K-12 kids, it is likely they will be asked questions they struggle to answer, which creates an impetus for them to deepen their own knowledge of engineering and science principles. The fourth criterion is the projects "must cover a considerable time span and be capable of fostering development over time" $[11$, p. 80]. With respect to this criterion, K-12 outreach programs vary substantially. In some cases, college students engage in "one off" events, for example badge days for Girls Scouts [14]. But in other programs, college students engage with engineering clubs weekly for a semester, or go into classrooms at least weekly. Thus, there are aspects of Dewey's learning theories that provide a framework to analyze the K-12 outreach experiences of college students.

Students may be motivated to engage in K-12 outreach activities for a variety of reasons. Engaging in service aligns with an Ethic of Care [15], and Schwartz's altruistic helping behavior model [16] explores the process leading to the decision to participate in service. The Service Learning Model [17] then explains how participating in service may influence the development of social values. These elements were combined into a Professional Social Responsibility Development Model (PSRDM) [18]. The current research is situated within a broader study that 
used the PSRDM to explore student attitudes toward socially responsible engineering.

This research explored the personal outcomes from undergraduate engineering student engagement with K-12 pupils, from the perspective of the students, and whether Dewey's four criteria for educative learning were connected with these descriptions.

\section{Methods}

The research was conducted post hoc, using transcripts from interviews with undergraduate students. The authors observed that a number of undergraduate engineering students talked about working with K-12 students in their interviews, which presented an opportunity to conduct this research. The larger study explored social responsibility attitudes through longitudinal interviews with undergraduate engineering students ([19]; IRB Protocol \#11-0414). Briefly, from among 244 first-year engineering students attending five universities who took an online survey in September 2012, 34 students were recruited to participate in interviews. The process of selecting and recruiting students to participate in the interviews included intentional over-sampling of female students (13 male, 21 female) and an explicit goal to represent a range of social responsibility (SR) attitudes (measured using 50 items on a 1-7 Likert scale), majors, and institutions [19]. Note that among all of the survey respondents, the average SR score was $5.5 \pm 0.6$ (range 3.5 to 7.0 ) in comparison to the interviewed group with an average SR score of $5.8 \pm 0.9$ (range 4.0 to 6.8 ); this difference resulted because a larger number of the students with low SR scores on the pre-survey declined to participate in the interviews. The four institutions represented among the 34 students interviewed in year 1 included: a large public institution with very high research activity located in the West (LPU; $n=11$ ); a medium-sized private institution with very high research activity located in the Northeast (PrU; $n=8)$; a medium-sized public institution with high research activity located in the Northeast (MPU; n=6); and a medium-sized public technically focused institution with high research activity located in the Midwest (TechU; $\mathrm{n}=9$ ). The students represented a range of different engineering majors, including mechanical, civil, environmental, chemical, biomedical, and computer science; a number of students changed majors over time. Some students also changed institutions and continued to engage in the research.

During the interviews, students were asked to discuss their experiences in engineering in general, as well as specific questions targeting social responsibility. No direct questions were asked during the interview about participating in outreach or service activities with K-12 students. However, students were asked what they were doing outside of class and school work, and this question led a number of students to discuss activities with K-12 students. The framing of the interviews around the theme of social responsibility may have also led some students to discuss their involvement with K-12 students as an example of activities they perceived to embody their social responsibilities. The interviews were primarily conducted by phone, about 30 to 60 minutes in duration, audio recorded, and transcribed. The interview transcripts were analyzed using emergent thematic coding to determine if the undergraduate students discussed K-12 related activities, and if so the types of those activities and associated outcomes from the perspective of the students. Deductive coding was also conducted using the four criteria from Dewey's learning theories, described by Giles and Eyler [11]: generate interest, worthwhile intrinsically, awaken need to learn, and time span. 
The interviews were conducted in spring 2013, 2014, 2015, and 2016 with students at the end of their first, second, third, and fourth year of college, respectively. Students participating in the interviews were invited to take an accompanying online survey (with a variable response rate to the survey). The number of interviews ranged from 34 in year 1 to 20 in year 4 . The full group of 34 students did not participate in interviews each year due to a variety of reasons; for example, 10 students left engineering/computing majors or the university altogether, and others did not respond to invitations to participate in the interviews. In addition, four students transferred to other universities but continued to participate in the interviews. Student pseudonyms are used in this paper. Students were compensated $\$ 100$ per interview and $\$ 10$ for taking the online surveys.

There are a variety of limitations to keep in mind when interpreting the results of the study. The students interviewed may or may not represent 'typical' engineering students. These students were initially attending four doctoral-awarding institutions, thus the full spectrum of institution types were not represented (such as liberal arts focused, bachelor's or Master's level institutions, religiously affiliated). The framing of the larger study was targeted to research social responsibility (SR) in engineering students. The students who participated in the interviews largely represented somewhat higher SR than their incoming first-year peers, despite efforts to recruit a more balanced cohort (described more fully in [19]). In addition, students were not asked explicitly whether or not they had participated in K-12 associated activities or the outcomes of such activities. But the lack of explicitly studying K-12 settings may have reduced the bias in student responses that may have resulted if they believed they were participating in research studying the outcomes of engaging in K-12 programs (e.g. exaggerate benefits due to socially desirable response / satisficing bias [20]). Among the 34 students interviewed, some may have participated in K-12 related activities but failed to reveal that information or discuss it during the interview. Thus, the results should be considered preliminary in nature as a first-step toward an intentionally designed study exploring the research question.

\section{Results and Discussion}

\section{Participation (or not) in K-12 Activities}

When asked what they were doing outside of class and school work, fifteen students (2 male, 13 female including 3 who left engineering) shared their experiences participating in various activities with K-12 students. The student characteristics are summarized in Table 1; basic characteristics of the remaining 19 students who did not discuss K-12 related activities in their interviews are included in the Appendix table. Among the 15 students who described their participation in K-12 activities at some point in their undergraduate studies, the average SR score entering college (PreSR) was $6.0 \pm 0.4$ (range 5.1 to 6.8) compared to $5.5 \pm 0.8$ among those who did not describe participation in K-12 activities (range 4.0 to 6.6; not high confidence of statistically significant difference based on the non-parametric independent samples MannWhitney U test, with asymptotic sig. in 2-sided test 0.089 from SPSS). Previous research found a correlation between undergraduate engineering student participation in volunteer activities (including a variety of community service activities) and social responsibility scores [21]. This correlation is logical; a higher sense of social responsibility is likely to motivate a student to participate in volunteer activities $[16,18]$. However, K-12 related outreach, tutoring, etc. are only 
one group among the wide range of volunteer activities readily available to college students (e.g. Engineers Without Borders).

Table 1. Demographics and K-12 experiences described by engineering undergraduate students

\begin{tabular}{|c|c|c|c|c|}
\hline Pseudonym & School & Major & PreSR & K-12 experience and year in college \\
\hline Derek & $\operatorname{PrU}$ & Mech & 6.3 & $\begin{array}{l}\text { Yr2 and Yr3 athlete group volunteered with elementary and middle school } \\
\text { kids each week teaching lessons about leadership, integrity, etc, while } \\
\text { instilling healthy, active habits. Ran summer robot camp before senior } \\
\text { year. }\end{array}$ \\
\hline Todd & TechU & Mech & 5.1 & Yr1 Mind Truckers - outreach to high school \\
\hline Ashley & $\operatorname{PrU}$ & $\mathrm{ChE}$ & 5.6 & $\begin{array}{l}\text { Yr1 work study at Boys and Girls club; Summer before Yr2 AmeriCorps } \\
\text { Vista }\end{array}$ \\
\hline Denise & $\operatorname{PrU}$ & Mech & 6.0 & $\begin{array}{l}\text { Yr1 internship doing K-12 outreach, continued K-12 teaching and } \\
\text { working with that group through senior year; summer tech camp K-3 } \\
\text { teaching }\end{array}$ \\
\hline Jamie & TechU & Mech & 5.6 & Summer camp counselor (prior to yr2) \\
\hline Jolene $^{\mathrm{T}}$ & M & Civ & 6.6 & Yr4 tutoring girl with ADHD \\
\hline Julie & $\operatorname{PrU}$ & Mech & 5.9 & Four years paid to work with K-12 outreach program \\
\hline Katherine & MPU & $\mathrm{EnCv}$ & 6.3 & Yr1 outreach to make high school students aware of engineering \\
\hline Kim & LPU & $\mathrm{EnCV}$ & 5.5 & $\begin{array}{l}\text { Yr3 and Yr4 volunteering at elementary schools about } 1 \text { hour per week } \\
\text { with an after-school engineering club for third to fifth graders }\end{array}$ \\
\hline Rachel & $\operatorname{PrU}$ & $\mathrm{CS}$ & 6.1 & Summer after Yr1 taught kids programming \\
\hline Tanya & TechU & Env & 6.1 & Yr4 K-12 outreach activities with NSBE \\
\hline Wynne & LPU & CvAr & 5.9 & $\begin{array}{l}\text { Yr1-3 K-12 outreach Legacy of Learning, STEM outreach SWE, hockey, } \\
\text { Girl Scouts; summer after Yr1 summer camp counselor as job }\end{array}$ \\
\hline Jocelyn ${ }^{\mathrm{L}, \mathrm{T}}$ & LPU-L & Mech & 6.8 & Yr1 SWE outreach director; paid work to teach at elementary school \\
\hline Lindsey $^{\mathrm{L}}$ & $\operatorname{PrU}$ & Biom & 6.0 & $\begin{array}{l}\text { Yr1 tutoring kids taking SATs, Summer engineering camps for kids; Yr1 } \\
\text { and Yr2 paid teaching in STEM in K-12 schools }\end{array}$ \\
\hline Miranda ${ }^{\mathrm{L}}$ & $\operatorname{PrU}$ & $\mathrm{ChE}$ & 6.0 & Helped high schoolers learn about university by working in admissions \\
\hline
\end{tabular}

The types of K-12 activities that students engaged in are summarized in Table 1. Notably, over half of the female students interviewed participated in some form of K-12 activity, in comparison to fewer of the male students. This gender difference may be due to female students having greater opportunity for these activities in association with the Society of Women Engineers (SWE) and similar groups dedicated to increasing the diversity of students in engineering and/or STEM. In previous research, Pickering et al. [8] noted "female engineers demonstrate a large interest in [K-12] outreach efforts" (p. 1), and that the engineering college students participating in the outreach program at their institution were $40-60 \%$ females (higher than $\sim 32 \%$ female students in engineering at the institution). Previous research identified higher participation rates in volunteer activities of female versus male undergraduate engineering students, among 1885 students at 17 universities [21]. More specifically, a higher percentage of female than male engineering students reported tutoring elementary and secondary students ( $54 \%$ vs. $43 \%$, respectively) [21]. Male students may be prioritizing spending their time on more traditional professionally-focused co-curricular activities (e.g. participating in the American Society of Mechanical Engineers, design competitions such as MiniBaja or American Society of Civil Engineers Concrete Canoe) rather than K-12 outreach. Support for this idea is found in the study by Simmons et al. [22] where overall out-of-class activity participation by undergraduate civil engineering students did not differ by gender but a higher percentage of female students 
participated in engineering outreach.

The majority of the students attending PrU discussed their participation in K-12 activities during the interviews ( 7 of 8), compared to fewer than half of the students attending the other institutions. Institutions may differ in the extent to which K-12 related activities are available to and/or promoted to engineering students.

Two of the female students (Julie and Denise) participated in an outreach program as a paid position all four years, while another (Wynne) conducted significant outreach activities for three years on a volunteer basis through various co-curricular and extracurricular groups such as the Society of Women Engineers and an Earthquake Engineering Research Institute student group. Other students discussed their participation in K-12 activities in only one or two years. Thus the time span element of students' participation in K-12 activities was quite variable.

\section{Limited by Time}

For many students, available time was an issue that may have limited their participation in K-12 related activities. The survey given at the end of the first year of college asked the students about factors that limited their participation in volunteer activities; all but one of the students indicated that lack of time due to coursework was a limiting factor; 17 noted lack of time due to extracurricular activities, and 14 a lack of time due to work. This relates to the criterion from Dewey that "truly educative projects" would require considerable time investment. Three specific examples of students who described their interest in K-12 outreach but lack of participation due to time constraints are provided. In Macy's year 1 interview she stated, "one of my friends does a program where she like goes and teaches preschoolers... [but I had] way too much to do during college... I wasn't really involved in anything this past year." Macy only participated in the interviews for 2 years, and again in year 2 reiterated that her coursework in chemical engineering at PrU kept her very busy and left time for little else.

In her interview near the end of her first year of college, Rachel described education as a social issue she was passionate about, when prompted to discuss social responsibility. She described concerns about inequity of women in math and sciences, drawing on her experiences at an allgirls high school. When asked about getting involved with those issues in college, Rachel responded:

I've been really focused on trying to pass my classes this first year. ... at [my university] there is this club that you can join where you go to [K-12] schools, and you teach grade schools about engineering with Legos and stuff like that. I think that would be really cool and I'm thinking about joining that later when I have time. ... they are trying to get women into more engineering and math fields. And I think that since that's such a big thing now, it will be easy to get into being an advocate for that....

Although not participating herself, Rachel's response speaks to her perception that the activity would be intrinsically worthwhile and it had clearly captured her interest. She later participated in K-12 teaching during a summer program where she was paid to teach programming.

Brandon in his year 2 interview stated:

I know that engineers where I work were going to high schools and talk to kids about science... [a friend] goes once a week or every other week or something to an elementary 
school and helps young girls out with their science or math homework. And things like that, I see myself really enjoying doing something like that... once I have time for that sort of thing....

Brandon (initially majoring in environmental engineering at TechU and later switching to civil engineering) participated in interviews all four years, but never discussed personally participating in outreach or other activities with K-12 kids. Lack of time was previously identified as the primary barrier for engineering students to participate in out-of-class activities in general [22].

\section{Limited Financially}

Providing money for students to participate in K-12 activities may be important. In the survey at the end of the first year, 9 of the 31 student respondents indicated that financial limitations constrained their participation in volunteer activities during college (including Brandon and Denise; 3 among the 34 students did not complete the online survey at the end of year 1). A number of students discussed their stress about loans and money (e.g. Alicia, Brandon, Miranda, Todd). A number of the students described having work-study jobs on campus (typically associated with financial need; Ashley, Macy, Wynne). Some of the students were working 30 hours per week to earn money for college (e.g. Jackie). A previous large study found that about $37 \%$ of the engineering students identified a job among their out-of-class activities [22]. A significant amount of time spent working at a paying job would leave little to no time other types of extra-curricular activities, including K-12 outreach. Thus, funding associated with K-12 outreach may be particularly important for low-income students struggling to pay for their education. There is evidence in this research that ten of the 15 students who discussed K-12 related activities were paid for some or all of these activities. Two of the female students participated in K-12 activities through all four years, and were paid to work with the program. Other students worked summer jobs associated with K-12 STEM camps. Being paid for K-12 activities makes them extrinsically worthwhile to student participants.

\section{Outcomes and Impacts from K-12 Activities}

$\underline{\text { Fun }}$

The theme that emerged the most frequently from students' descriptions of their K-12 outreach experiences included how fun it was (13 of 15). Many described their K-12 activities as a good break from the stress of classes and studying. This balance and reconnecting with the fun of engineering might help students persist in their engineering studies. This speaks to the interest element of educative projects from Dewey. Tanya in her year 2 interview described, “...because I help with the water Festival here at the [de-identified] society and there were kids from local schools around the community and I managed a lot of water activities and that was a blast. There was so much fun. So I can't wait to do it this summer. Working with kids is fun." Kim noted of her involvement once per week with an afterschool program for third to fifth graders, "...it's pretty cool. Sometimes before I'm like, oh I don't want to go, but then I come back and I'm like, that was actually really fun.... it's always nice to get away from school work for a little bit." This fun setting may provide an ideal site for learning, in alignment with deep learning attributes (e.g. "reducing the pressure and stress of evaluation" [23, p. 8]).

Similarly, Rachel in her year 2 interview noted, "I get paid for teaching now, but besides that, 
mostly it's just a feeling afterwards. It's very calming and it's a nice sort of, it's kind of my free time and it's a nice way to spend my free time I guess."

In regards to K-12 and her other volunteer activities Miranda described in her year 1 interview: I think for me being involved at school, like whether it be helping kids decide where they want to go to college like through admissions stuff that I've done on campus and giving back to the University as a volunteer... I think in helping others I take a mental break from what I'm doing academically and I think that helps me become a more well-rounded person, whether it be applying my prior knowledge from academics or whether it just be something fun or social. Something volunteer-wise is just something that has helped me maintain my sanity.

Thus, participation in these K-12 activities that are fun and a break from their schoolwork may be helpful for the students to maintain balance and a positive mental state. This idea of (school)work-life balance as an important outcome of engaging in fun out-of-class activities has been previously explored [23].

\section{Teaching and Technical Outcomes}

The teaching aspects of these programs may solidify engineering concepts for the undergraduates, as teaching a concept is a great way to learn. Seven students explicitly discussed teaching elements. For example, Tanya in her year 2 interview stated, "I'm in this program [deidentified] which is where you mentor children and teach them about water ecology and just have a fun time with them and teach them about environmental engineering." This "teaching" element aligns with Dewey's [12] criterion that a learning the experience should "awaken curiosity for information" [11].

Denise, a Hispanic first-generation student majoring in Mechanical Engineering, was paid in Year 2 to work with a program that brought engineering into the classrooms in local schools. She describes learning from a more senior student involved in the program with whom she was paired, as well as learning from the fifth graders, “... I learned a lot from the kids too. We made simple machines and each week ... because of all the learning the first semester I felt very prepared the second semester and now we're focused on electrical engineering and teaching them how to use circuits..." So it appears that Denise may be solidifying her own knowledge of core engineering concepts through the experience, similar to findings in Yowell et al. [2]. The quote also returns to the importance of time span, since Denise contrasts her first and second semester experiences. Another student who was in the same program for all four years, Julie, noted: "I like learning about the technologies and things to teach with... but I don't personally like teaching it." So the student recognizes she is learning in order to teach the kids, but dislikes the actual teaching part.

In year 2, Rachel, a computer science major, described her job the previous summer teaching middle school and high school students programming. She noted, "it was interesting to be on the teaching side of that rather than the learning side..." It is likely that she became much better at her own programming abilities through teaching it, although she doesn't explicitly indicate in her response that she has come to that realization. This perhaps illustrates the lost opportunity that required reflection could have provided. 
The skill of teaching itself is likely helpful in the workforce as an engineer, given that most engineers eventually move into roles where they are mentoring more junior colleagues. For example, after spending about 5-minutes describing her experiences with a weekly K-12 outreach program that she had participated in during all four years of college, Julie stated, "Part of my personal responsibility is becoming a mentor... you can do that with your company [with someone] who is starting off in that position that you started off in and moving through the ranks..." Thus, reflecting on her K-12 teaching/outreach involvement during the interview perhaps triggered this thought about future mentoring roles after college during her work as an engineer.

\section{Professional Skills}

It was clear that some of the undergraduate students were developing communication, interpersonal, and teamwork skills through their K-12 involvement. Four of the students explicitly discussed communication skills and two discussed teamwork aspects. When asked "what were some things that you learned out of that experience" in relation to her summer job with AmeriCorps Vista after her first year of college, Ashley noted:

Mostly working with people. How to better articulate my ideas especially when you're teaching math and you have to think of different ways to go around it. If you're at the Science Museum and you're trying to explain stuff and you're with children you can use words that they've never heard and that was very interesting....

This quote alludes to benefits in her interpersonal and communication skills via teaching. Communication skill enhancement for undergraduate students is the most common outcome previously described in the literature (e.g. $[2,5,7])$.

\section{Giving Back}

A number of the students discussed the idea of giving back and serving as a role model for kids. This giving back theme aligns with Dewey's criteria of being intrinsically worthwhile. In her year 4 interview, Wynne (an architectural engineering student) described:

$\ldots$ over the summer in my internship we had a day where we got some underprivileged schools from around the area and we had a day where they came in and we taught them about construction. And they were encouraged to ask us questions and I felt like the kids were inclined to talk to me because I was younger and they were more comfortable coming and asking me questions. ... teaching kids about construction and teaching them about the professional world, [was] a good opportunity for us to give back.

This echoes Wynne's previous descriptions of her K-12 outreach engagement in college during her third year interview, largely through the Society of Women Engineers. She recognized that she was a role model to inspire girls to pursue engineering, "You want to get this image of a white male in a lab coat out of their minds. ... all the local groups and events like that have really helped me feel like I can give back to the community in that way. It's just kind of sharing my own knowledge and experiences."

Jocelyn spoke at length about her involvement in after school engineering clubs at two local schools in year 1, and a desire to inspire girls to pursue engineering. (Sadly, largely as a result of being really unhappy during an internship after her second year of college she later left engineering herself). 
Derek participated in a weekly outreach program with other athletes in year 2 and 3 of college, and this seemed largely motivated by giving back, noting "we support schools in the surrounding area and I think it helps, what's the term, at risk schools or the lower income students... we go there once a week and we meet with the students in the classroom and I guess there's a small group of five for each classroom and we have some lessons. .... I think it's good for the kids because they get a chance to get active and it gives them a chance to hang out with us, so I hope we can be good role models."

\section{Diversity and Social Justice}

A number of the students were working in schools that were very different from the schools they attended as children; specifically, schools with a high degree of cultural diversity or in lowincome settings. A few students commented on this as broadening their experience. The most indepth direct discussion of this was by Julie, reflecting back on her time in college during the fourth year interview:

Where I'm originally from is a very homogeneous population, like 95\% white and everyone was fairly affluent. I think coming to [PrU] was kind of a culture shock where people are telling you all the time to 'check your privilege'... that literally was said every day by someone. So being at a school like [PrU] which was particularly into social activism I think definitely just drove it home for me that that is a thing that is important and just having had opportunities to work with communities that really just made me think like wow okay, this is a totally different world and these people are not given the same opportunities that I have. ...one of my [outreach] classrooms that I spent an entire year in was in [inner city location] and so their population was completely different than any that I have really interacted with in the past. They are probably $60 \%$ Chinese students and some of them have real language barriers and then the other $40 \%$ is African-American students. So their schools are super not well-funded and their classrooms are not really even classrooms ... it's more like we really can't afford to have walls. So that was a time I felt like my work [in the outreach program] was the most important because I have been in schools that were ridiculously nice and wellfunded and do not need [us]. Yet we are still going in. The kids still really like it and I think it's really fun, but I think it's more important to be a role model for these underprivileged kids who have probably never met an engineer and don't know what are the opportunities for them in the STEM fields. So that specifically is an experience that I would point to that kind of opened my eyes a little bit to just kind of the nature of the world outside my bubble I guess.

The result of this experience made Julie more aware of inequalities at a societal level, giving her a first-hand perspective related to social justice issues.

Other students who discussed issues around poverty in the schools where they worked included Derek and Ashley. For example, in the year 2 interview, Derek described participating in a program where student athletes:

support schools in the surrounding area and I think it helps, what's the term, at risk school or the lower income students and I think their school actually burned down two years ago. So we go there once a week and we meet with the students in the classroom.... I think it's good for the kids because they get a chance to get active and it gives them a chance to hang out with us, so I hope we can be good role models. And they don't come from necessarily the greatest, like the most, I don't want to sound...from the most privileged neighborhood, but 
usually we support them and tell them that we believe in them.

During the year 4 interview, Derek included in his definition of social responsibility "making the community better and it helps making yourself better and others better because you're part of the community." Asked what led him to this definition, in particular over the past year, Derek cited his involvement with kids as part of a robotics camp and a sleep away camp for kids who are affected or infected by HIV, AIDS, or sickle cell disease. He linked these experiences to his sense of personal rather than professional social responsibility, and stated "I guess I never really saw a connection between social responsibility and my job." But then, after prompting, noted, "I think engineering is a very customer and end-user focused industry. ... for me I would love my job to make some sort of impact." So there is the sense that Derek in his role as a mechanical engineer will be somewhat sensitive to the impact of his work on a broad range of people.

\section{$\underline{\text { Attitudes }}$}

A variety of affective outcomes are possible from participation in K-12 outreach activities. Ashley described her summer experience with AmeriCorps Vista as, "it was very fun, it was very tiring and very fun. ... [I learned] a lot of patience." While no students directly stated that their K-12 experiences made them more confident, through many of their descriptions of the experience it seemed that this was the case. The students gained confidence in their engineering abilities, even though this outcome may not have been recognized. These attitudes fostered through K-12 engagements may promote attitudes supportive of professional engineering practice, such as confidence, consideration of others, persistence, respect, and tolerance [24]. Similar themes were mentioned by a number of students. Again, structured reflection may have made these attitude-related outcomes more apparent to students and improved their ability to articulate how their K-12 outreach activities fostered attitudes that will be of benefit in professional settings.

\section{Sense of Community}

An element that came through in some cases was that the students felt like part of a supportive community. Through the program, they had closer interactions with faculty, college staff, graduate students, and/or other undergraduates (e.g. Denise, "So there are full-time faculty that work there all the time and there are graduate students working there... building relationships"). In the interview at the end of her first year, Julie noted "I actually know a lot of people there [in the outreach program] and they are probably my favorite people at [PrU]. They are doing some of the coolest work and it's just like incredible people." These connections might be particularly important as students are finding their place at a new institution. Derek was part of a program where his hockey team went out to local at-risk schools once per week, with about five college students in each class. His description implied it brought the college students closer, in addition to bonding with the K-12 kids. Thus, structured activities among the cohort of university students and college faculty/staff may be beneficial attributes of K-12 programs.

\section{Future Work}

The key limitation of the current study was the lack of explicit questions on students' participation in K-12 activities, why they did or did not choose to participate, and what they gained. Questions could also explicitly probe students' perceptions of the extent to which their experiences did or did not encompass the four elements of Dewey's learning model. Interviewing 
students longitudinally is a strong research method that could be utilized in future work. An interview immediately prior to engagement could ask students about their motivations, whereas a later interview could probe outcomes. Intentionally recruiting students participating in programs with different characteristics and attributes would also be worthwhile, such as an intensive twoday camp with kids versus an after-school program, primary versus secondary kids, etc. However, researchers should cautiously consider the extent to which students volunteering to participate in a research study on the outcomes of K-12 engagement are representative of all student participants; students opting to participate are perhaps more likely to be aware that they are deriving benefits from the engagement and therefore interested in talking about it. In addition, steps should be taken to ensure that students don't feel pressured to claim benefits that they don't personally feel due to a satisficing or acquiescence bias [20], telling you what they think you want to hear.

\section{Implications}

As college faculty and staff design K-12 outreach programs, they should consider the benefits to undergraduate students engaged with their programs. This "systems" perspective on the benefits to the college students and K-12 students is likely to improve the overall program. Dewey's four criteria for educative projects (generate interest, worthwhile intrinsically, problems that demand new information, and cover a considerable time span) that have been applied in service-learning settings [11] may optimize student learning. Programs are encouraged to engage the same college students multiple times, which should benefit both student learning and their quality facilitating the K-12 program. To the extent possible, if programs are able to compensate students financially for their involvement this may remove a barrier for participation, particularly for lower income students. Programs should build community among faculty, college staff, and peers. Sending pairs of undergraduate students or an undergraduate with a graduate student might be particularly effective. Perhaps most importantly, the programs should incorporate reflection activities. These need not be formal, written 'assignments', but rather could be directed group discussions. These discussions could serve multiple roles as a debrief to explore how to improve the experience, as well as helping the students begin to reflect on their experience. With thoughtful design of K-12 engagement activities, a range of technical, professional, and personal learning outcomes can result, regardless of whether the activity is embedded within courses as service-learning or conducted by students for pay or as volunteer activities.

\section{Acknowledgements}

This material is based on work supported by the National Science Foundation under Grant \#1158863. Any opinions, findings, and conclusions or recommendations expressed in this material are those of the author(s) and do not necessarily reflect the views of the National Science Foundation.

\section{References}

[1] Jeffers, A.T., A.G. Safferman, S.I. Safferman. 2004. Understanding K-12 Engineering Outreach Programs. Journal of Professional Issues in Engineering Education and Practice, 130 (2), 95-108.

[2] Yowell, J.L., M.S. Zarske, D. Knight, J.F. Sullivan. 2013. Impact of TEAMS clubs: an afterschool engineering enrichment program that impacts K-12 students and college student leaders. American Society for Engineering Education Annual Conference \& Exposition, Paper ID \#6369. 17 pp. 
[3] Albers, L., A. Smith, 2008. The impact of out-of-school time (OST() math and science clubs on elementary and middle school students, teachers, schools and the undergraduate and graduate fellows that facilitate them. American Society for Engineering Education Annual Conference \& Exposition, Paper AC 2008-1907, 22 pp.

[4] Ernst, J.V., L. Bottomley, E.A Parry, J.P. Lavelle. 2011. Elementary Engineering Implementation and Student Learning Outcomes. American Society for Engineering Education (ASEE) Annual Conference \& Exposition. Paper AC 2011-227, 12 pp.

[5] Anthony, A.B., H. Greene, P.E. Post, A. Parkhurst, and X. Zhan. 2016. Preparing university students to lead K12 engineering outreach programmes: a design experiment. European Journal of Engineering Education, 41 (6), 623-637.

[6] Carberry, A., M. Portsmore, C. Rogers. 2007. The effects of STOMP on students' understandings of and attitudes toward the engineering design process. American Society for Engineering Education Annual Conference \& Exposition, Paper AC 2007-1137, 16 pp.

[7] Caldwell, K., J. McCoy, L. Albers, A. Smith, E. Parry. 2007. The impact of K-12 outreach programs on graduate and undergraduate experiences. American Society for Engineering Education Annual Conference \& Exposition, Paper AC 2007-2234. 23 pp.

[8] Pickering, M., E. Ryan, K. Conroy, B. Gravel, M. Portsmore. 2004. The Benefit of Outreach to Engineering Students. Proceedings of the American Society for Engineering Education (ASEE) Annual Conference \& Exposition. Session 1692. 12 pp.

[9] Bielefeldt, A.R., J. Lewis, M. Polmear, D. Knight, N. Canney, C. Swan. 2020. Educating civil engineering students about ethics and societal impacts via co-curricular activities. Journal of Civil Engineering Education. In press.

[10] Cress, C.M., C. Burack, D.E. Giles, J. Elkins, M.C. Stevens. 2010. A Promising Connection: Increasing College Access and Success through Civic Engagement. Campus Compact, Boston MA. 32 pp.

[11] Giles, D.E. and J. Eyler. 1994. The theoretical roots of service-learning in John Dewey: Toward a Theory of Service-Learning. Michigan Journal of Community Service Learning, 1(1), 77-85.

[12] Dewey, J. 1933. How We Think. Boston: D.C. Heath \& Co.

[13] Bielefeldt, A.R. 2015. Student Learning Outcomes from Service-Learning K-12 Outreach in a First-Year Introduction to Engineering Course. Proceedings of the American Society for Engineering Education (ASEE) Rocky Mountain Section Conference. April 10-11. Denver, CO. 13 pp.

[14] Fry, C.C., J. Davis, Y. Shirzi-Fard. 2008. Recruitment and retention of females in the STEM disciplines: The annual Girl Scout day camp at Baylor University. $38^{\text {th }}$ ASEE / IEEE Frontiers in Education Conference, Oct. 22-25, Saratoga Springs NY, 5 pp.

[15] Gilligan, C. 1982. In a Different Voice: Psychological Theory and Women's Development, Cambridge, MA: Harvard University Press.

[16] Schwartz, S.H. 1977. Normative influences on altruism. Advances in Experimental Social Psychology, 10, 221279.

[17] Delve, C.L., S.D. Mintz, G.M. Stewart. 1990. Promoting values development through community service: A design, New Directions for Student Services, 50, 7-29.

[18] Canney, M., A. Bielefeldt. 2015. A framework for the development of social responsibility in engineers. International Journal of Engineering Education, 31(1B), 414-424.

[19] Rulifson, G. 2015. Evolving social responsibility understandings, motivations, and career goals of undergraduate students initially pursuing engineering degrees. Dissertation. University of Colorado Boulder.

[20] Holbrook, A.L., M.C. Green, J.A. Krosnick. 2003. Telephone vs. face-to-face interviewing of national probability samples with long questionnaires: comparisons of respondent satisficing and social desirability response bias. Public Opinion Quarterly, 67 (1), 79-125.

[21] Canney, N.E., A.R. Bielefeldt. 2015. Volunteerism in engineering students and its relation to social responsibility. American Society for Engineering Education Annual Conference \& Exposition, Paper ID \#12231, 12 pp.

[22] Simmons, D.R., Y. Ye, M.W. Ohland, K. Garahan. 2017. Understanding students' incentives for and barriers to out-of-class participation: Profile of civil engineering student engagement. Journal of Professional Issues in Engineering Education \& Practice. 144 (2): 04017015.13 pp.

[23] Purchase, J.M., D.R. Simmons. 2017. Exploring the meaning of fun: A missed opportunity to retain underrepresented groups in engineering? American Society for Engineering Education Annual Conference \& Exposition, Paper ID \#18745, 14 pp.

[24] ASCE. 2008. Civil Engineering Body of Knowledge for the $21^{\text {st }}$ Century: Preparing the Civil Engineer for the Future. Second Edition. ASCE; Alexandria VA. 
Appendix. Students who participated in one or more interviews but did not discuss any K-12 related activities

\begin{tabular}{|c|c|c|c|c|c|}
\hline Pseudonym & School & Major(s) & $\begin{array}{l}\text { Yrs without } \\
\text { Interview }\end{array}$ & $\begin{array}{l}\text { Notes on Other Volunteering Significant } \\
\text { College Activities (survey or interview) }\end{array}$ & $\begin{array}{l}\text { Pre } \\
\text { SR }\end{array}$ \\
\hline Macy & PrU & ChemE & 3,4 & Summer work study on campus; food pantry & 5.5 \\
\hline Brandon & TechU & Env-Civil & & Student government; summer internships & 5.8 \\
\hline Jason & TechU & Mech & & Co-op, hockey, music & 4.7 \\
\hline Madison & TechU & Mech & & Research, other work on/off campus & 4.9 \\
\hline Nathan & TechU & Civil & & EWB, study abroad, IM sports & 6.1 \\
\hline Sarah & TechU & Civil & 4 & Work, rowing team & 6.6 \\
\hline Kaitlin $\mathrm{L}, \mathrm{T}$ & MPU-L & Env-LAr-IntlDev & 4 & Struggled in courses, left eng/MPU after yrl & 6.1 \\
\hline Maggie $^{\mathrm{L}}$ & MPU & Civil-ASci-IntlDev & 4 & Eng too narrow, scholarship/grade concerns & 6.0 \\
\hline Nelson $^{\mathrm{L}}$ & MPU & Env-EnvStud-left & 3,4 & Undergraduate research & 4.8 \\
\hline Travis ${ }^{\mathrm{L}}$ & MPU & EnvE-left & 4 & Suspended, mental health issues & 4.0 \\
\hline Trevor & MPU & Env-Civil & & Alternate energy racing, work, IM sports & 5.5 \\
\hline Alicia $^{\mathrm{L}}$ & LPU & Mech-IntegPhysiol & 4 & Soup kitchen and humane society volunteer & 5.6 \\
\hline Jackie & LPU & Mech & 3,4 & Large number of hours for work & 4.9 \\
\hline Katie $^{\mathrm{L}}$ & LPU & Civil-EnvStudies & 4 & Marching band, crew team & 6.6 \\
\hline Quinn & LPU & Civil-CS & 3 & Intl student & 5.3 \\
\hline Shawn & LPU & Env-ChemE & & Biodiesel team, IM sports, honor society & 6.5 \\
\hline Thomas L,T & LPU-L & Mech-Geosci & 4 & Job, disaster relief volunteer, donates blood & 4.0 \\
\hline Tim L,T & LPU-M & Mech-left-? & $2,3,4$ & ROTC & 6.5 \\
\hline Tucker & LPU & Civil & & Prof. societies: ASCE, AGC; research & 5.5 \\
\hline
\end{tabular}

${ }^{\mathrm{L}}$ Leaver: transferred out of engineering / computing major after year 1 or 2 ; ${ }^{\mathrm{T}}$ Transferred institutions

Two students left college entirely (Nelson, Travis); Tim transferred to a medium public institution; Kaitlin and Thomas transferred to different large public institutions. Data drawn from interviews and/or online surveys. 